\title{
Cucurbitacin B inhibits cell proliferation and induces apoptosis in human osteosarcoma cells via modulation of the JAK2/STAT3 and MAPK pathways
}

\author{
ZHI-REN ZHANG ${ }^{1}$, MING-XIA GAO ${ }^{2}$ and $\mathrm{KAI} \mathrm{YANG}^{3}$ \\ ${ }^{1}$ Department of Orthopedics, Zhumadian Central Hospital, Zhumadian, Henan 463600; ${ }^{2}$ Department of Health Management, \\ Dongying People's Hospital, Dongying, Shandong 257000; ${ }^{3}$ Department of Joint Surgery, \\ Zhengzhou Central Hospital Affiliated to Zhengzhou University, Zhengzhou, Henan 450007, P.R. China
}

Received October 20, 2015; Accepted February 27, 2017

DOI: $10.3892 /$ etm.2017.4547

\begin{abstract}
Osteosarcoma (OS) is the most commonly diagnosed tumor of the bones in children and young adults. Even with conventional therapies the 5-year survival rate is $\sim 65 \%$ in patients with OS. Considering the side effects and aggressiveness of malignant bone tumors, research is focussing on multi-targeted strategies in treatment. Cucurbitacin B, a triterpenoid compound has been demonstrated to induce apoptosis in various cancer cell types. The Janus kinase 2/signal transducer and activator of transcription 3 (JAK2/STAT3) signalling cascades and mitogen activated protein kinases (MAPK) signalling cascades are critical regulators of tumorigenesis. The present study assessed the influence of cucurbitacin B on the viability and expression of MAPKs and proteins of the JAK2/STAT3 cascades in human OS cells (U-2 OS). Cucurbitacin B (20-100 $\mu \mathrm{M})$ significantly reduced cell viability $(\mathrm{P}<0.05)$ and induced apoptosis, as assessed by MTT and Annexin V/propidium iodide staining, along with inhibiting cell migration. Gelatin zymography revealed supressed activities of matrix metalloproteinase (MMP-)2 and 9. Furthermore, cucurbitacin B effectively upregulated the apoptotic pathway and caused the effective inhibition of MAPK signalling and JAK2/STAT3 cascades. Multifold suppression of vascular endothelial growth factor by cucurbitacin B was also observed, indicating inhibition of angiogenesis. Thus, by downregulating major pathways-MAPK and JAK2/STAT3 and MMPs, cucurbitacin $\mathrm{B}$ has potent anti-proliferative and anti-metastatic effects that require further investigation with regards to cancer treatment.
\end{abstract}

Correspondence to: Dr Kai Yang, Department of Joint Surgery, Zhengzhou Central Hospital Affiliated to Zhengzhou University, 195 Tongbai Road, Zhengzhou, Henan 450007, P.R. China E-mail: yangkaiykk@hotmail.com

Key words: apoptosis, cucurbitacin, Janus kinase/signal transducer and activator of transcription pathway, mitogen activated protein kinases, osteosarcoma

\section{Introduction}

Osteosarcoma (OS) a primary sarcoma of the bones that primarily affects children and adolescents accounting for $\sim 5 \%$ of pediatric tumors (1). OS affects the distal long bones, the femur and tibia (1) and is generally characterized by its local invasion of bone and soft tissues, loss of the affected extremity's functions and distant metastasis (2). Multimodal conventional therapies including radiation, surgical resection and chemotherapy are employed to treat OS $(3,4)$. Despite the combination therapy approach, limited improvement has been observed in the 5 -year survival rate $(65 \%)$ of patients with OS (5). Furthermore, these therapeutic approaches often lead to severe side effects such as cardiotoxicity, hearing loss and nephrotoxicity, and may also cause drug resistance and increase the risk of local relapse (6). Thus, improved targeted approaches are required, with no or less side effects.

The Janus kinase 2 (JAK2)/signal transducer and activator of transcription 3 (STAT3) signalling pathway serves a critical role in cell survival and division. Activated JAK2/STAT3 signalling cascade influences the expression of numerous proteins that are associated with various physiological functions, including cell cycle regulation and apoptosis. The JAK/STAT3 pathway regulates the expression level of anti-apoptotic proteins [B-cell lymphoma-extra large (Bcl-xL) and myeloid leukemia cell differentiation protein (Mcl-1)] (7), cell cycle regulatory proteins (cyclin D1, p21, and p27) (8) and mitochondrial apoptosis pathway related proteins [ $\mathrm{Bcl}-2$ associated X (Bax), cytochrome $c$ and caspase-3] (9). Furthermore, STAT3 activation promotes angiogenesis by inducing vascular endothelial growth factor (VEGF) (10), and also stimulates invasion and metastasis by increasing the expression of matrix metalloproteinases (MMPs) (11). The pathway is considered as a major molecular target of interest in a number of cancer types, including melanoma (12), renal carcinoma (13) and breast cancer (14).

The mitogen-activated protein kinases (MAPKs) signalling cascades are a large family of serine/threonine kinases that control and regulate various physiological process, including cell survival and apoptosis, and are also involved in tumorigenesis. The functions of MAPK signalling in cancer development are complex, as they regulate wide range of cellular responses (15). 
Activated MAPK pathway stimulates cell growth or induces apoptosis based on the stimuli $(16,17)$. Numerous studies have reported that the c-Jun N-terminal kinases (JNK), p38 and extracellular signal-regulated kinases (ERK1/2) cascades exert a vital role in regulating cytotoxic drug induced apoptosis in OS $(18,19)$. Thus, targeting the pathway may have clinical value in the treatment of OS.

Accumulating research data indicate that plant-derived compounds are much more effective in inhibiting cancer cell proliferation and inducing apoptosis (20). Phytochemicals are reported to elicit antitumor effects by inducing cellular defense system, antioxidant enzymes system and also inhibition of anti-cell growth signalling and anti-inflammatory pathways culminating in apoptosis and/or cell cycle arrest (21-24).

Cucurbitacins were initially identified in the Cucurbitaceae plant family, which includes cucumber and are also isolated from various plant families (25). Owing to their effective pharmacological properties, plants rich in cucurbitacins have been widely used in traditional Chinese medicine for their analgesic, anti-inflammatory, antimicrobial, antipyretic, antitumor activities and hepatoprotective effects (25-28). Researchers have reported that cucurbitacin I may inhibit cancer cell growth by disrupting the JAK/STAT3 signaling pathway in both in vitro and in vivo tumor models $(29,30)$. Studies have reported that cucurbitacin B inhibits the growth of various human cancer cell lines and tumor xenografts including breast, prostate, lung, uterine cervix, liver, skin and brain cancer $(18,31,32)$. Considering the biological effects cucurbitacin $B$, the present study aimed investigate the effects of cucurbitacin B on human OS cells and assess whether it modulates the JAK/STAT3 and MAPK signalling pathways.

\section{Materials and methods}

Reagents and chemicals. Cucurbitacin B, glutamine, RPMI 1640 medium, fetal calf serum (FCS), penicillin, streptomycin and $0.25 \%$ trypsin were purchased from Sigma Aldrich; Merck KGaA (Darmstadt, Germany). Antibodies against ERK1/2 (cat. no. 9102), phospho-ERK1/2 (cat. no. 9101), p38 (rabbit mAb, cat. no. 8690), phospho-p38 (rabbit mAb, cat. no. 4511), JNK (cat. no. 9252), phospho-JNK (mouse mAb, cat. no. 9255), MMP-2 (rabbit mAb, cat. no. 87809), MMP-9 (cat. no. 852) (all from Cell Signaling Technology, Danvers, MA, USA), Bcl-xL (cat. no. sc-8392), Bcl-2-associated death promoter (Bad) (cat. no. sc-8044), Bax (cat. no. sc-4239), Bcl-2 (cat. no. sc-509), VEGF (cat. no. sc-4571), caspase-9 (cat. no. sc-81663), caspase-8 (cat. no. sc-81656), caspase-3 (cat. no. sc-176260), p-JAK2 (cat. no. sc-34479), JAK2 (cat. no. sc-34479), p-STAT3 (cat. no. sc-56747) and STAT3 (cat. no. sc-482) (all from Santa Cruz Biotechnology, Inc., Dallas, TX, USA) were used for expression analysis. All other reagents used in the study were purchased from Sigma Aldrich; Merck $\mathrm{KGaA}$, unless otherwise stated.

Cell lines and culture. Human osteosarcoma cell line, U-2 OS was obtained from the Cell Bank of Shanghai Institute of Biochemistry and Cell Biology (Chinese Academy of Sciences, Shanghai, China). The cells were cultured and maintained in RPMI-1640 medium supplemented with 10\% FCS, $2 \mathrm{mM}$ glutamine, streptomycin $(100 \mu \mathrm{g} / \mathrm{ml})$ and penicillin $(100 \mathrm{U} / \mathrm{ml})$ at $37^{\circ} \mathrm{C}$ in a humidified atmosphere with $5 \% \mathrm{CO}_{2}$.
Measurement of cell viability. OS cells were seeded into 96 -well plates $\left(5 \times 10^{5}\right.$ cells/well $)$ and incubated at $37^{\circ} \mathrm{C}$ for $24 \mathrm{~h}$. On reaching $70 \%$ confluence, the cells were treated with different concentrations of cucurbitacin B (20, 40, 80 and $100 \mu \mathrm{M}$ ) for $24 \mathrm{~h}$. Cells were then incubated at $37^{\circ} \mathrm{C}$ with MTT for $4 \mathrm{~h}$. The formazan crystals formed were dissolved with dimethyl sulfoxide and the absorbance was measured at $570 \mathrm{~nm}$ using a Thermo Multiskan Spectrum (Thermo Fisher Scientific, Inc., Waltham, MA, USA).

Analysis of apoptosis by Annexin $V$ assay. OS cells were incubated at $37^{\circ} \mathrm{C}$ with various concentrations of cucurbitacin $\mathrm{B}$ (20, 40, 80 and $100 \mu \mathrm{M})$ for $24 \mathrm{~h}$. Following incubation, cells were treated with $0.25 \%$ trypsin, washed twice with ice-cold PBS and harvested for detection of apoptosis using an Annexin V-FITC apoptosis detection kit (BD Biosciences, Franklin Lakes, NJ, USA), according to the manufacturer's instructions. The cells were washed in PBS at $1 \times 10^{6}$ cells $/ \mathrm{ml}$ and suspended at $1 \times 10^{5} / 100 \mu \mathrm{l}$ binding buffer (BD Biosciences) containing FITC-conjugated anti-Annexin V antibody (provided in the kit) and PI, and analyzed for fluorescence using a flow cytometer (FACSCalibur; BD Biosciences).

Determination of morphological changes by Hoechst staining. Morphological changes of the U-2 OS cells following treatment with cucurbitacin B was determined by Hoechst staining. Briefly, the OS cells were seeded at a density of $5 \times 10^{4}$ cells per well in a 6 -well plate and cultured at $37^{\circ} \mathrm{C}$ for $12 \mathrm{~h}$ and treated with cucurbitacin B $(20,40,80$ and $100 \mu \mathrm{M})$ for $48 \mathrm{~h}$. The cells were then fixed with $4 \%$ paraformaldehyde in PBS for $10 \mathrm{~min}$, washed with PBS and stained with Hoechst $33258(5 \mathrm{mg} / \mathrm{l})$ for $15 \mathrm{~min}$ at room temperature in the dark. The cells were observed under a a fluorescence microscope (Nikon Eclipse TiS coupled with NIS-Elements imaging software; Nikon Corporation, Tokyo, Japan). The cells undergoing apoptosis were characterized by condensed or fragmented nuclei.

Wound healing assay. The influence of cucurbitacin B on the cell migration of U-2 OS cells was assessed. In brief, $5 \times 10^{5}$ cells were maintained in $10 \mathrm{~cm}$ Petri plates and incubated for 24-72 h until they reached complete confluency and were wounded using a $200 \mu \mathrm{l}$ pipette tip. All cells in the plates were treated with final concentrations of cucurbitacin B (25, 50 and $100 \mu \mathrm{M} ; 3$ plates for each concentration) and then were incubated at $37^{\circ} \mathrm{C}$ in fresh culture medium for $24 \mathrm{~h}$. The migration of the cells in the wounded area was measured as previously described (33). Cell migration was determined as a percentage of the cell-free area compared with the area of the initial wounded area. The fields were photographed using an inverted microscope (Nikon Eclipse TS2; Nikon Corporation).

Gel zymography. Gel zymography was performed to evaluate the activities of MMP-2 and MMP-9. Sample preparation was done as previously described by Mizoguchi et al (34). Samples were run on SDS-PAGE (10\%) gels that contained $0.1 \%$ gelatin under non-reducing conditions. Triton X-100 $(2.5 \%)$ was used to wash the gels to remove SDS, then the gels were washed further in incubation buffer $(50 \mathrm{mM}$ Tris $\left.\mathrm{HCl}, 0.15 \mathrm{M} \mathrm{NaCl}, 10 \mathrm{mM} \mathrm{CaCl}_{2}\right)\left(25 \pm 2^{\circ} \mathrm{C}\right)$ for $30 \mathrm{~min}$ and 
incubated $\left(24 \mathrm{~h}, 37^{\circ} \mathrm{C}\right)$. Following incubation, the gels were stained with Coomassie Brilliant Blue (1\% Coomassie Brilliant Blue G-250, 30\% methanol and 10\% acetic acid) for $3 \mathrm{~h}$ and then were destained (7\% acetic acid, $40 \%$ methanol) until clear bands representing gelatinolysis were seen against dark background. By using an Atto Densitograph Software Library Lane Analyser (Atto Instruments, Inc., Rockville, MD, USA) the total activity was determined.

Western blot analysis. Following treatment with cucurbitacin B (25, 50 and $100 \mu \mathrm{M}), \mathrm{U}-2$ OS cells were washed twice with ice-cold PBS and centrifuged at 10,000 x g for $5 \mathrm{~min}$ at $4^{\circ} \mathrm{C}$. The cells were treated in ice-cold hypotonic lysis buffer (10 mM HEPES pH 7.9, $1.5 \mathrm{mM} \mathrm{MgCl}_{2}, 0.2 \mathrm{mM} \mathrm{KCl}, 0.5 \mathrm{mM}$ dithiothreitol, $0.2 \mathrm{mM}$ phenylmethyl-sulphonylfluoride), vortexed for $2 \mathrm{~min}$, centrifuged at $12,000 \mathrm{x}$ g for $10 \mathrm{~min}$ at $4^{\circ} \mathrm{C}$ and the supernatants were collected and assayed for protein content using the Bradford method (35). Equal amounts of protein samples $(60 \mu \mathrm{g})$ were subjected to electrophoresis in $12 \%$ SDS-PAGE and the bands were then transferred to nitrocellulose membranes (GE Healthcare Lifesciences, Chalfont, UK). The membranes were washed and blocked using blocking buffer (5\% non-fat dry milk/0.1\% Tween-20 in TBS) for $1 \mathrm{~h}$ at room temperature. They were then incubated overnight at $4^{\circ} \mathrm{C}$ with respective primary antibodies followed by incubation at room temperature for $40 \mathrm{~min}$ with horseradish peroxidase-conjugated-secondary antibody (mouse mAb; Cell Signaling Technology, cat. no. 7076; dilution 1:1,000). The immunoreactive bands were detected by enhanced chemiluminescence procedure (GE Healthcare Lifesciences). Protein expression levels were normalized with the expression levels of $\beta$-actin using anti- $\beta$-actin antibody (AC-15) from Santa Cruz Biotechnology, Inc. (cat. no. sc-69879; dilution 1:1,000). The positive signals from the immunoblots $(n=3)$ were quantified using Image Lab Software (v5.1) (Bio-Rad Laboratories, Inc., Hercules, CA, USA).

Statistical analysis. The data are presented as mean \pm standard deviation, from three or six individual experiments. The values were analyzed by one-way analysis of variance followed by Duncan's Multiple Range Test. All statistical analyses were performed using the SPSS software (version 22.0; IBM SPSS, Armonk, NY, USA). P<0.05 was considered to indicate a statistically significant difference.

\section{Results}

Cucurbitacin B inhibits $U-2$ OS cell proliferation. The viability of osteosarcoma cells following treatment with cucurbitacin B was determined by MTT assay, and the findings are presented in Fig. 1. Osteosarcoma cells treated with different concentrations of cucurbitacin B $(20,40,80$ and $100 \mu \mathrm{M})$ exhibited reduced cell proliferation in a concentration-dependent manner. The viability percentage of U-2 OS cells treated with cucurbitacin $\mathrm{B}$ at $20 \mu \mathrm{M}$ was $83 \%$, whereas following the $100 \mu \mathrm{M}$ dose, the cell viability significantly decreased to $21 \%$ $(\mathrm{P}<0.05$; Fig. 1).

Influence of cucurbitacin B on cell viability counts and morphological changes in U-2 OS cells. The results of MTT

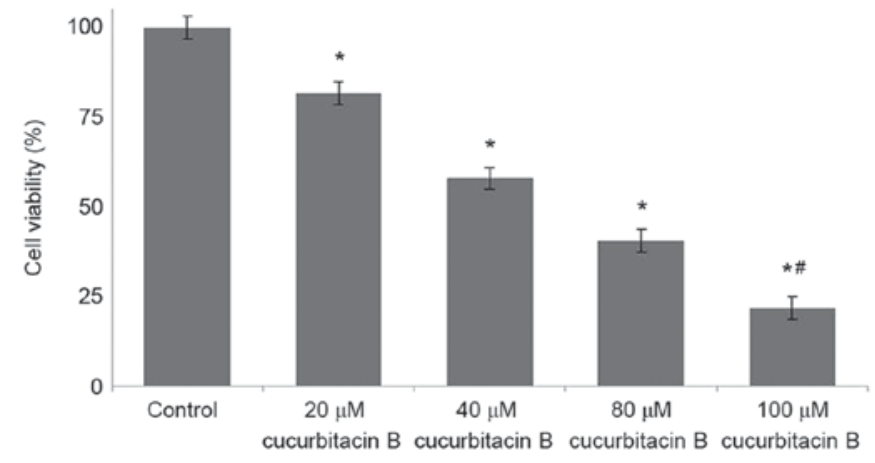

Figure 1. Cucurbitacin B reduces the cell viability of $\mathrm{U}-2$ OS cells. ${ }^{*} \mathrm{P}<0.05$ vs. control; ${ }^{\#} \mathrm{P}<0.05$ vs. $20 \mu \mathrm{M}$. Data are presented as mean \pm standard deviation, $\mathrm{n}=3$. OS, osteosarcoma.

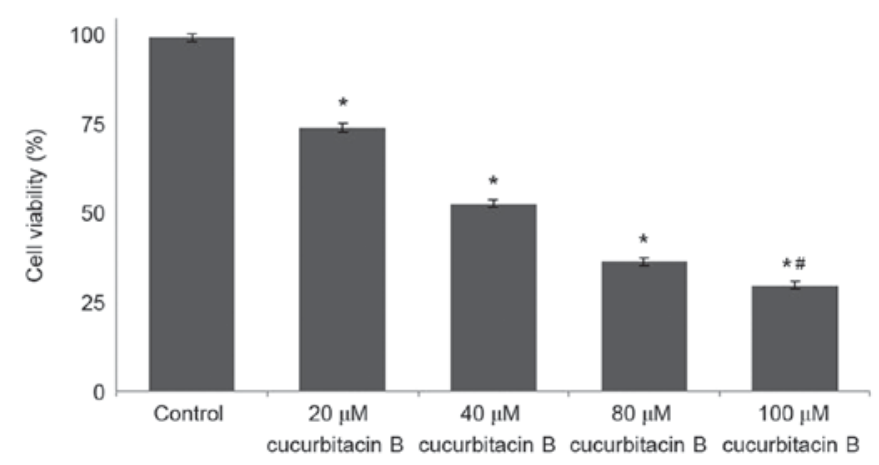

Figure 2. Cucurbitacin B induces apoptosis of human osteosarcoma U-2 OS cells. Cucurbitacin B was observed to significantly increase the apoptotic cell count and reduce cell viability in U-2 OS cells. ${ }^{*} \mathrm{P}<0.05$ vs. control; ${ }^{\#} \mathrm{P}<0.05$ vs. $20 \mu \mathrm{M}$. Data are presented as mean \pm standard deviation, $\mathrm{n}=3$. OS, osteosarcoma.

assay revealed that cucurbitacin B may effectively reduce the viability of U-2 OS cells. The present study further analyzed whether cucurbitacin B reduced viability by inducing apoptosis. Annexin V/PI staining assay was performed to determine apoptotic cell counts. Exposure to cucurbitacin B was identified to significantly increase the apoptotic cell counts $(\mathrm{P}<0.05$; Fig. 2), in a dose-dependent manner with $100 \mu \mathrm{M}$ concentration exhibiting maximum effects.

Furthermore, Hoechst 33258 staining was performed to assess morphological changes in the U-2 OS cells following cucurbitacin B treatment. Following treatment for $48 \mathrm{~h}$, the chromatin of U-2 OS cells was condensed and appeared to be brighter and deeper. Notably, treatment with cucurbitacin at higher concentrations of 80 and $100 \mu \mathrm{M}$ demonstrated deeper staining of nuclear chromatin than the lower doses (20 and $40 \mu \mathrm{M})$. Highly condensed and stained chromatin indicates characteristics of apoptotic cells, thus suggesting that cucurbitacin B effectively induced apoptosis in U-2 OS cells. The percentage of apoptotic cells increased significantly following cucurbitacin B treatment $(20,40,80$ or $100 \mu \mathrm{M})$ compared with the control $(\mathrm{P}<0.05$; Fig. 3$)$.

Cucurbitacin B inhibits migration of U-2 OS cells. Following incubation with cucurbitacin B $(25,50$ and $100 \mu \mathrm{M})$ for $24 \mathrm{~h}$, the area of the wound was measured. In the cells that were not treated with cucurbitacin $\mathrm{B}$, the distance between the scratches 


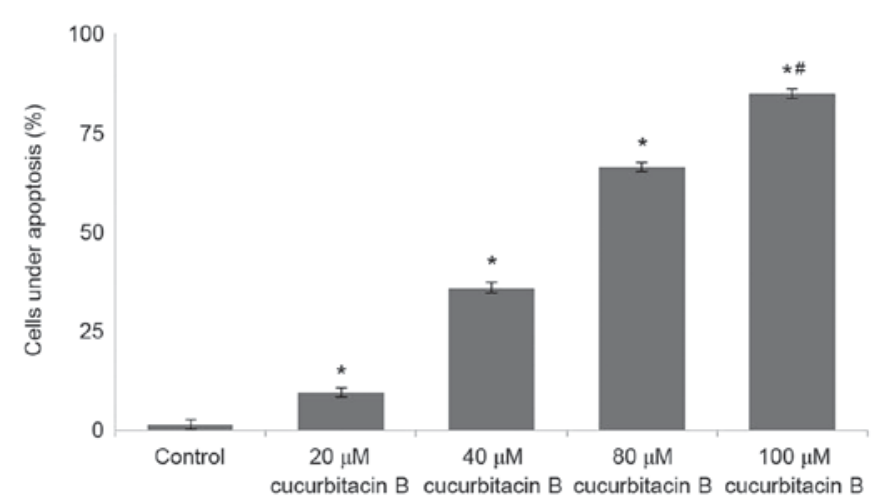

Figure 3. Influence of Cucurbitacin B on the viability of U-2 OS cells under Hoechst staining. Hoechst staining using a fluorescence microscope (Nikon Eclipse TiS coupled with NIS-Elements imaging software) revealed a significantly increased number of cells under apoptosis following cucurbitacin B treatment. ${ }^{*} \mathrm{P}<0.05$ vs. control; ${ }^{\prime} \mathrm{P}<0.05$ vs. $20 \mu \mathrm{M}$. Data are presented as mean \pm standard deviation, $n=3$. OS, osteosarcoma.

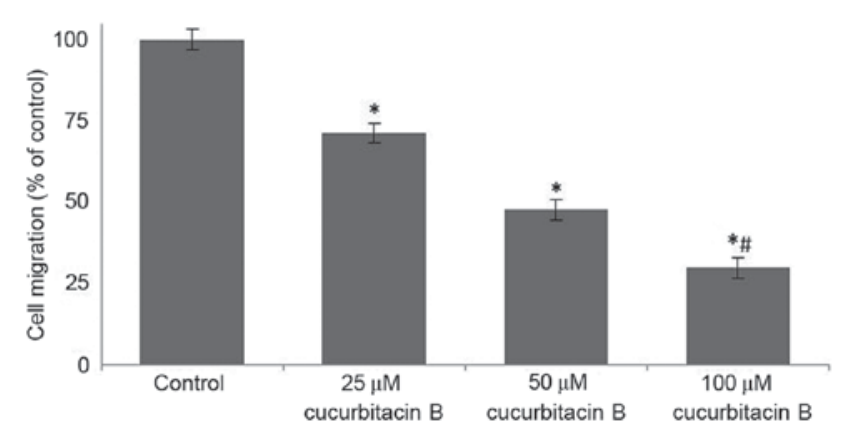

Figure 4. Influence of cucurbitacin B on cell migration determined by a wound healing assay. Cucurbitacin B exposure significantly reduced cell migration of the U-2 OS cells over the wound area in a dose-dependent manner. ${ }^{*} \mathrm{P}<0.05$ vs. control; ${ }^{\#} \mathrm{P}<0.05$ vs. $25 \mu \mathrm{M}$. Data are presented as mean \pm standard deviation, $\mathrm{n}=6$. OS, osteosarcoma.

was significantly reduced when compared with U-2 OS cells that were exposed to cucurbitacin, in a dose-dependent manner $(\mathrm{P}<0.05)$. In the OS cells that were incubated with cucurbitacin $B$ the cell free area was evidently increased, the distance increased with concentration of cucurbitacin B (Fig. 4). The growth and movement of the cells in the cell free scratch area observed in cells that were not treated with cucurbitacin suggests cell division and migration were occuring, which were supressed following cucurbitacin B treatment.

Cucurbitacin B downregulates MMPs. It has been established that MMPs principally contribute to the invasion and metastasis of tumor cells (36-38). In the present study, to further assess whether cucurbitacin inhibits MMPs, the expression of MMP-2 and -9 were determined by gel zymography and western blot analysis. The result of the current study indicated that cucurbitacin B exposure at all assessed concentrations caused marked inhibitions in the expressions of MMPs (Fig. 5A). The zymography analysis revealed significantly supressed activities of MMP-2 and -9 in a dose-dependent manner (Fig. 5B). Furthermore, western blot analysis revealed a markedly decreased expression level of MMP2 and MMP9 in cucurbitacin B-treated cells. However, relatively little inhibition was observed following treatment with $25 \mu \mathrm{M}$ cucurbitacin
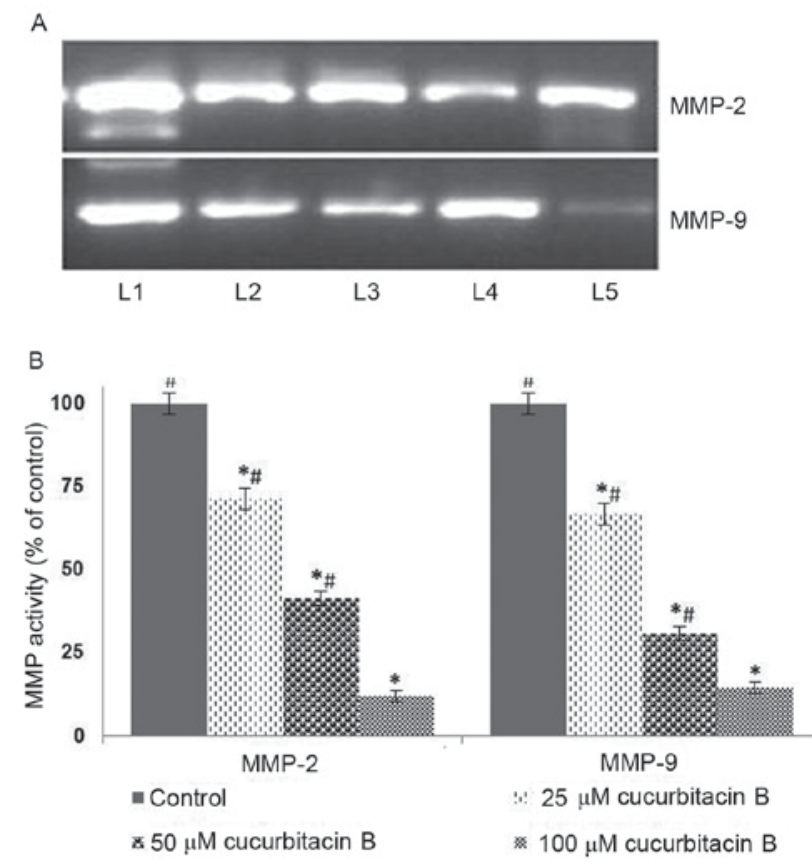

C

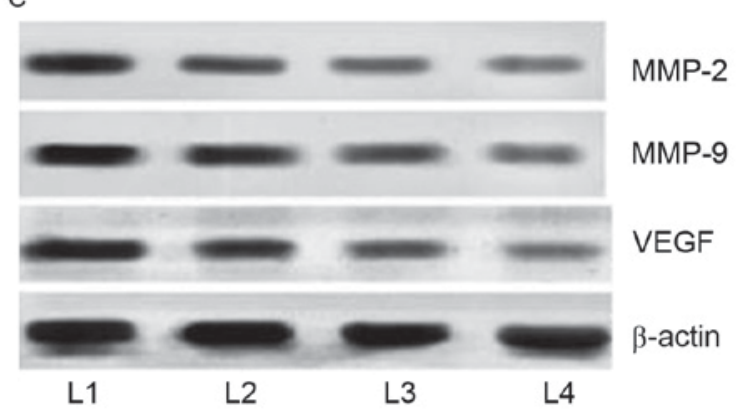

Figure 5. Cucurbitacin B reduces activities of MMP-2, MMP-9 and VEGF in U-2 OS cells. This was determined by (A) gelatin zymography following exposure to cucurbitacin $\mathrm{B}$, indicating marked downregulation in the expressions of MMP-2 and -9, (B) quantified results from the gelatin zymography indicating a significant downregulation of MMP activity. (C) Western blot analysis indicates a marked reduction in the expression of MMP-2, MMP-9 and VEGF. ${ }^{*} \mathrm{P}<0.05$ vs. control; ${ }^{\#} \mathrm{P}<0.05$ vs. $25 \mu \mathrm{M}$. Data are presented as mean \pm standard deviation, $n=3$. MMP, matrix metalloproteinases; VEGF, vascular endothelial growth factor; OS, osteosarcoma; L1, control; L2, $20 \mu \mathrm{M}$ cucurbitacin B; L3, $40 \mu \mathrm{M}$ cucurbitacin B; L4, $80 \mu \mathrm{M}$ cucurbitacin B; L5, $100 \mu \mathrm{M}$ cucurbitacin B.

when compared with higher doses, 50 and $100 \mu \mathrm{M}$. Furthermore, marked suppression of VEGF levels was also observed following cucurbitacin B exposure in a dose-dependent manner (Fig. 5C). These observations suggest that cucurbitacin B was able to markedly supress cell migration and inhibit angiogenesis, potentially by downregulating the expression of MMP2, MMP9 and VEGF.

Influence of cucurbitacin B on the expressions of apoptotic pathway proteins. Apoptosis is a coordinated network of genes that lead to cell death and is the target pathway in many anticancer therapies. Anticancer drugs are known to induce apoptosis by targeting cells that harbour genetic damage or that divide inappropriately (39). The present study assessed the influence of cucurbitacin B on the expression of apoptotic pathway proteins in U-2 OS cells to investigate the molecular events 
A

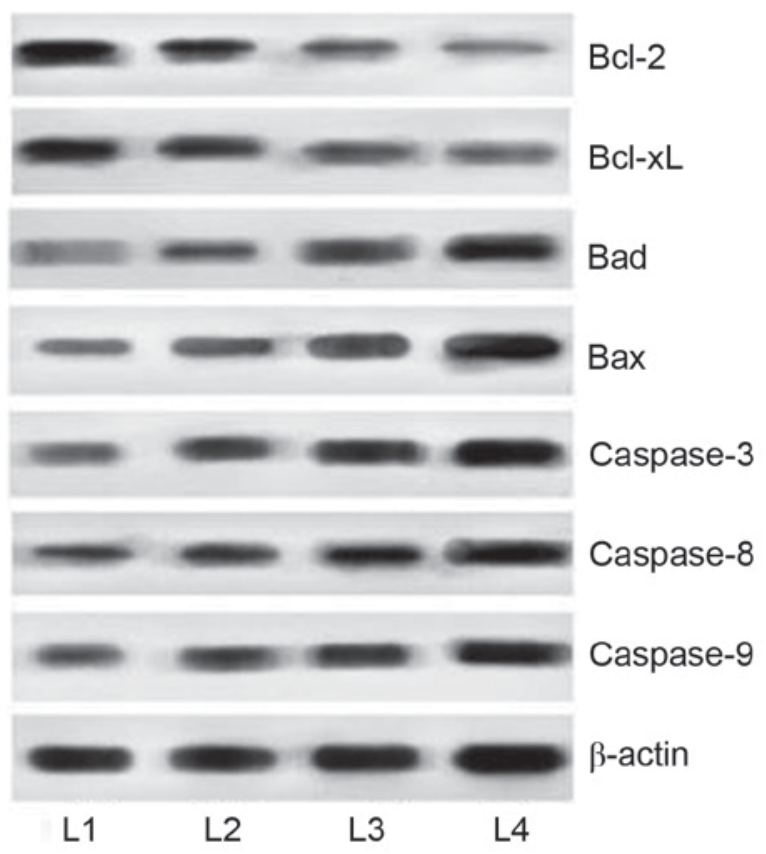

$\mathrm{B}$

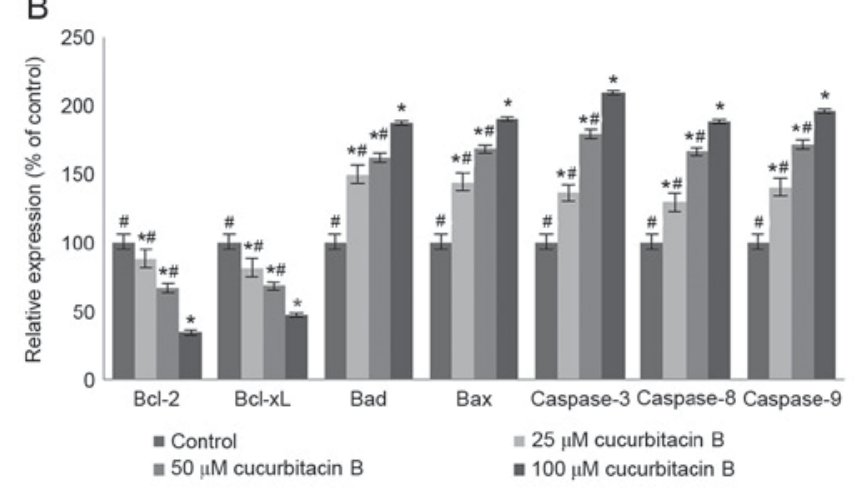

Figure 6. Cucurbitacin B modulates the expression of apoptosis pathway proteins. Cucurbitacin B caused effective upregulation of caspase-3, - 8 and -9 in addition to an increase in the expression of Bax and Bad, while suppressing the expression of Bcl-2 and Bcl-xL, demonstrated in (A) western blot analysis and (B) quantification of the results. ${ }^{*} \mathrm{P}<0.05$ vs. control; ${ }^{~} \mathrm{P}<0.05$ vs. $100 \mu \mathrm{M}$. Data are presented as mean \pm standard deviation, $\mathrm{n}=3$. Bcl-2, B-cell lymphoma 2; Bcl-xL, Bcl-2 extra large; Bad, Bcl-2-associated death promoter; Bax, Bcl-2 associated X; L1, control; L2, $25 \mu \mathrm{M}$ cucurbitacin B; L3, $50 \mu \mathrm{M}$ cucurbitacin B; L4, $100 \mu \mathrm{M}$ cucurbitacin B.

associated with cucurbitacin-induced cell death. A significant increase in the expression of caspase- $3,-8$ and -9 in the U-2 OS cells exposed to cucurbitacin B was observed following western blot analysis $(\mathrm{P}<0.05$; Fig. 6). The activation of caspase- 9 and -8 have previously been documented, suggesting the involvement of intrinsic and extrinsic apoptotic pathways that subsequently lead to the activation of caspase-3 (40). Therefore, in the present study the enhanced expression of caspases by cucurbitacin $B$ indicates an increased level of apoptosis in U-2 OS cells.

Furthermore, the expression of Bcl-2 family members was also assessed under the influence of cucurbitacin B. The Bcl-2 family are key proteins in the regulation of intrinsic mitochondrial pathways of apoptosis, specifically controlling the release of cytochrome $c$, which further regulates the caspases cascade $(41,42)$. The Bcl-2 family comprises anti-apoptotic (Bcl-2 and Bcl-xL) and pro-apoptotic proteins [Bax, Bcl-2

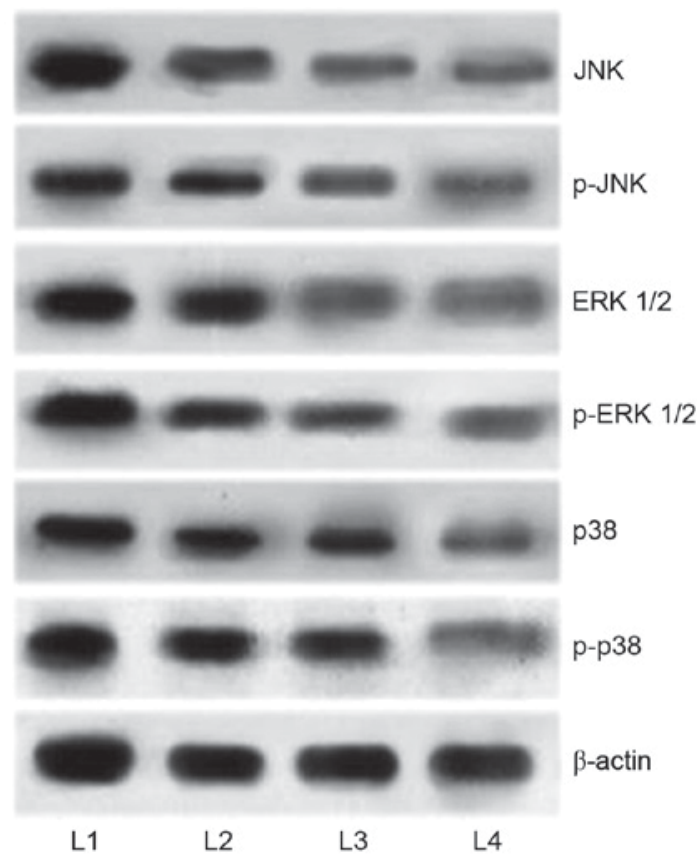

Figure 7. Cucurbitacin B downregulates the expression of MAPK signalling cascades. Cucurbitacin B exposure markedly inhibited the activation of JNK, ERK1/2 and p38, thus inhibiting the signaling pathway, demonstrated by western blot analysis. MAPK, mitogen activated protein kinases; JNK, c-Jun N-terminal kinases; ERK, extracellular signal-regulated kinases; p-JNK, phosphorylated-JNK; p-ERK, phosphorylated ERK; L1, control; L2, $25 \mu \mathrm{M}$ cucurbitacin B; L3, $50 \mu \mathrm{M}$ cucurbitacin B; L4, $100 \mu \mathrm{M}$ cucurbitacin B.

antagonist killer (Bak) and Bad] (43). Cucurbitacin B exposure resulted in a multi-fold increase in the Bad and Bax protein expression $(\mathrm{P}<0.05$; Fig. 6B) with significant downregulation of Bcl-2 and Bcl-xL expression ( $\mathrm{P}<0.05$; Fig. 6B). The upregulated expression of Bax and Bad indicates the activation of the apoptotic pathway. Therefore, with enhanced levels of pro-apoptotic proteins, cucurbitacin B aids in elevated levels of caspases, which eventually induces apoptosis.

Cucurbitacin modulates the MAPK signalling cascades. It has been well documented that activation of MAPK pathways serves a critical role in inhibiting apoptosis. In the present study, in order to elucidate the mechanisms underlying cucurbitacin B-induced apoptosis, the expression levels of MAPK cascade proteins, JNK, p-JNK, p38, p-p38, ERK1/2, and p-ERK1/2 were analyzed by western blot analysis. The results demonstrated an enhanced expression of the proteins in the U-2 OS cells that were not exposed to cucurbitacin (Fig. 7). However, U-2 OS cells treated with cucurbitacin B exhibited marked downregulation in the phosphorylated levels of ERK1/2, p38 and JNK. Whereas substantial decreases were observed in the expression levels of p38 and ERK1/2, JNK and p-JNK levels were decreased to a lesser extent. However, marked inhibitions were observed following cucurbitacin $\mathrm{B}$ treatment at all the three assessed concentrations, with $100 \mu \mathrm{M}$ exerting maximum effects. The results indicated that the downregulation of the MAPK signalling pathway may have aided in induction of apoptosis of the U-2 OS cells.

Effects of cucurbitacin B on the JAK2/STAT3 signalling pathway. The JAK/STAT3 pathway serves a pivotal 
A
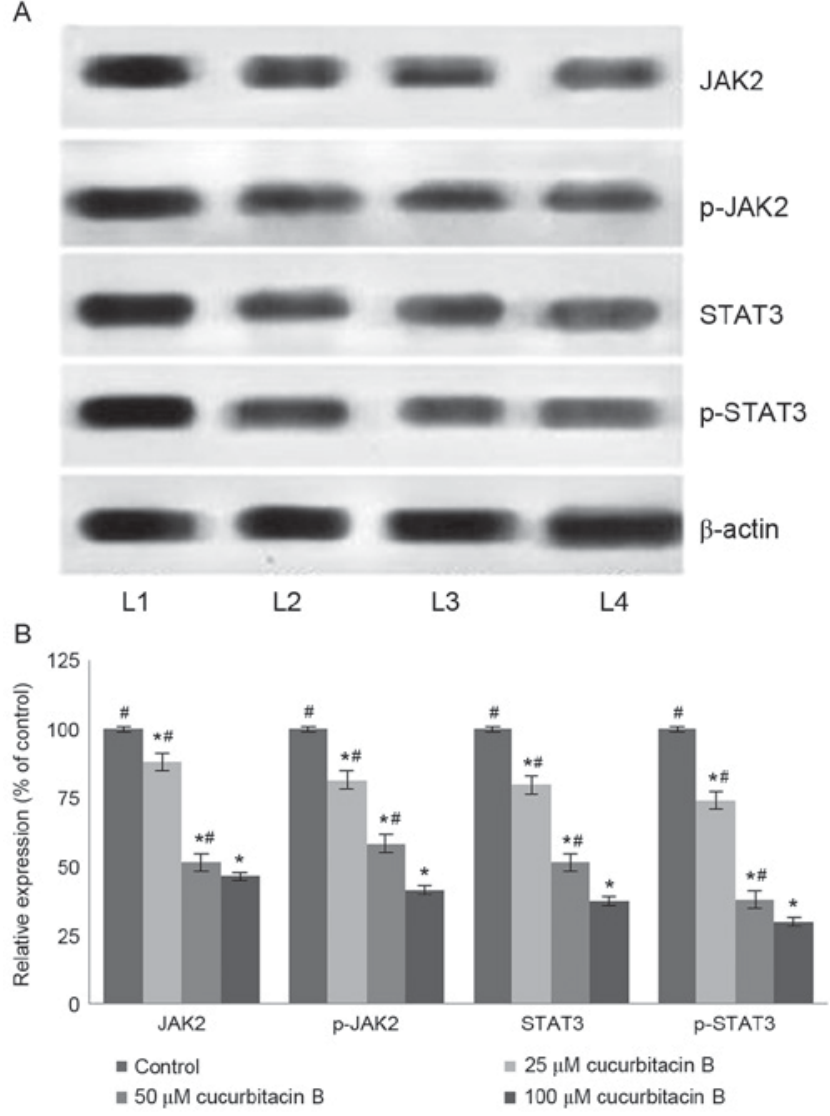

Figure 8. Cucurbitacin B downregulates the expression of JAK2/STAT3 signalling cascades. (A) Western blot analysis indicates that cucurbitacin B induced marked downregulation of JAK2 and STAT3 expression, thereby inhibiting the signaling cascade and (B) quantified results indicate a significant reduction in expression of JAK2/STAT3 signaling cascades. ${ }^{*} \mathrm{P}<0.05$ vs. control; ${ }^{\#} \mathrm{P}<0.05$ vs. $100 \mu \mathrm{M}$. Data are presented as mean \pm standard deviation, $\mathrm{n}=3$. JAK2, Janus kinase 2; STAT3, signal transducer and activator of transcription 3; L1, control; L2, $25 \mu \mathrm{M}$ cucurbitacin B; L3, $50 \mu \mathrm{M}$ cucurbitacin $\mathrm{B}$; L4, $100 \mu \mathrm{M}$ cucurbitacin $\mathrm{B}$.

role in the transduction of a multitude of signals that are critically involved in the development and homeostasis in mammals (44). STAT3 has been reported to be constitutively activated in different types of cancer in humans (45). It has been demonstrated that the inhibition of STAT3 leads to apoptosis and inhibition of cancer cell proliferation (46). In the present study, western blot analysis was performed to assess the expression level of phosphorylated forms of JAK2 and STAT3 following exposure to cucurbitacin B. The results of the current study indicate that cucurbitacin $B$ treatment significantly reduced the levels of activated JAK2 and STAT3 (P<0.05; Fig. 8). Cucurbitacin B at $100 \mu \mathrm{M}$ concentration caused a multi-fold decrease in the expression of STAT3 and JAK2. Furthermore, the inhibition of STAT3 and JAK2 expression was dose-dependent. Therefore, these observations indicate that cucurbitacin significantly inhibited the STAT3/JAK2 pathway and this may have a part in the increase rate of apoptosis observed.

\section{Discussion}

Cucurbitacins are widely used in traditional Chinese medicines and are the bitter principles of Cucurbitaceae $(25,47)$.
Cucurbitacin B, which is one of the most abundant cucurbitacins (27) exhibits anti-inflammatory activity and is used traditionally to treat hepatitis $(28,48)$. Previous studies have demonstrated the antitumor activities of cucurbitacin B in various human cancer cell lines and tumor xenografts $(49,50)$. However, the mechanisms underlying the anticancer activities are yet to be elucidated. Studies are currently focussing on the identification and development of small molecules that inhibit major cell signalling pathways, as an important strategy in anticancer drug research (51-53). The present study investigated the effects of cucurbitacin $\mathrm{B}$ on cell proliferation and the MAPK and JAK2/STAT3 pathways in U-2 OS cells.

Inhibition of cell proliferation is an important indicator of anticancer activity. Treatment with cucurbitacin B $(20-100 \mu \mathrm{M})$ exhibited evident growth inhibition. Furthermore, cucurbitacin B markedly induced the apoptosis of U-2 OS, as observed by Hoechst staining and flow cytometry analysis followed by Annexin V/PI staining. The events underlying the induction of apoptosis were also analysed. Apoptosis occurs via the intrinsic mitochondrial pathway and the extrinsic membrane death receptor pathways. Cucurbitacin B exposure caused marked activation and enhanced expression of caspase-9, -8 and -3 . These observations suggest that cucurbitacin B induces apoptosis via the intrinsic pathway, which is in accordance with a previous study using chemotherapeutic drugs as gallic acid (54). Furthermore, Liu et al (55) reported that the majority of chemotherapeutic drugs were able to induce apoptosis through the intrinsic mitochondrial pathway.

The mitochondria-dependent apoptotic pathway is governed by Bcl-2-family proteins that includes pro-apoptotic (BH3-interacting domain death agonist, Bax, and Bak) and anti-apoptotic (Bcl-2 and $\mathrm{Bcl}-\mathrm{xL}$ ) proteins $(56,57)$. Bax promotes apoptotic factors and induces apoptosis, whereas Bcl-2 inhibits the release of pro-apoptotic proteins (58). Cucurbitacin B notably enhanced the expression of Bad and Bax and supressed the levels of Bcl-xL and Bcl-2 indicating activation of the intrinsic apoptotic cascade.

Cancer metastasis presents a huge challenge in cancer therapy and thus, blocking cancer cell metastasis is an important approach. MMPs serve crucial roles in metastasis, angiogenesis and also cause the release of growth factors from the extra cellular matrix (59). MMP-2 and -9 are well documented to be associated with the invasive metastatic potential of tumor cells (60). In U-2 OS cells a markedly enhanced expression of MMP-2 and -9 was observed. Cucurbitacin B supressed the levels of MMP-2 and -9 at all the tested doses and inhibited the activities of the enzymes, thus exhibiting anti-metastatic activity. The observations of the cell migration assay also reveal the potent effects of cucurbitacin B on the inhibition of cell migration and therefore, metastasis.

The JAK/STAT3 pathway is one of the major pathways that regulate and control various vital physiological processes. JAK activation exerts critical roles in cell proliferation, differentiation, migration and apoptosis $(44,61)$. Activated JAKs phosphorylate cellular substrates, including the STAT family, which are vitally associated with oncogenic signalling pathways (62). Constitutive activation of STAT3 is typically observed in cancer cells and has been demonstrated to serve a critical role in tumor cell growth and survival in human solid tumors $(62,63)$. STAT3 also upregulates anti-apoptotic proteins 
as Mcl-1 and Bcl-xL $(63,64)$. Therefore, blocking the pathway may aid in the inhbition of cancer cell growth and promotion of apoptosis. Treatment with cucurbitacin B was observed to markedly downregulate the level of phosphorylated STAT3 and JAK2 in a dose-dependent manner. The reduced level of Bcl-2 and Bcl-xL were also in line with STAT3 levels. Treatment with cucurbitacin $\mathrm{B}$ exhibited a marked reduction in the level of phosphorylated STAT3 and its downstream targets, such as cyclin B1 and Bcl-2 in the human laryngeal cell line Hep-2 (65). Furthermore, downregulated expression of VEGF was observed, which may be due to potent inhibition of STAT3. In the present study cucurbitacin B treatment downregulated JAK2/STAT3 signalling and also significantly upregulated mitochondrial apoptotic pathway-related proteins (Bax, Bad and cleaved caspases).

It has also been demonstrated that members of the MAPK family are important regulators of stress responses, in addition to being associated with cell survival and modulating the induction of apoptosis $(66,67)$. Cucurbitacin B was identified to effectively inhibit the activation of JNK, ERK1/2 and p38 in U-2 OS cells. Studies have reported that ERK1/2, the key molecule of the MAPK signalling pathway (68), is associated with promotion of tumor invasion and metastasis (69). Therefore, by inhibiting the activation of ERK1/2, cucurbitacin $\mathrm{B}$ effectively contributes to the inhibition of metastasis in line with MMP suppression.

In conclusion, cucurbitacin B significantly downregulates MAPK signalling and JAK2/STAT3 cascades and induces apoptosis in U-2 OS cells. The downregulation of MMPs and VEGF aid in the inhibition of invasion, metastasis and angiogenesis. Therefore, these findings indicate that cucurbitacin B is a potential potent candidate for OS therapy in the future. Further experiments under in vivo conditions will be required to confirm the effects of cucurbitacin B. Furthermore, the mechanisms associated with the protective effects of cucurbitacin B should be explored in more detail.

\section{References}

1. Thayanithy V, Park C, Sarver AL, Kartha RV, Korpela DM, Graef AJ, Steer CJ, Modiano JF and Subramanian S: Combinatorial treatment of DNA and chromatin-modifying drugs cause cell death in human and canine osteosarcoma cell lines. PLoS One 7: e43720, 2012.

2. Guijarro MV, Ghivizzani SC and Gibbs CP: Animal models in osteosarcoma. Front Oncol 4: 189, 2014

3. Federman N, Bernthal N, Eilber FC and Tap WD: The multidisciplinary management of osteosarcoma. Curr Treat Options Oncol 10: 82-93, 2009.

4. Jaffe N: Osteosarcoma: Review of the past, impact on the future. The American experience. Cancer Treat Res 152: 239-262, 2009.

5. Han XR, Sun Y and Bai XZ: The anti-tumor role and mechanism of integrated and truncated PDCD5 proteins in osteosarcoma cells. Cell Signal 24: 1713-1721, 2012.

6. Luetke A, Meyers PA, Lewis I and Juergens H: Osteosarcoma treatment-where do we stand? A state of the art review. Cancer Treat Rev 40: 523-532, 2014.

7. Rajendran P, Li F, Manu KA, Shanmugam MK, Loo SY, Kumar AP and Sethi G: $\gamma$-tocotrienol is a novel inhibitor of constitutive and inducible STAT3 signalling pathway in human hepatocellular carcinoma: Potential role as an antiproliferative, pro-apoptotic and chemosensitizing agent. Br J Pharmacol 163: 283-298, 2011.

8. Huang JS, Chuang LY, Guh JY, Huang YJ and Hsu MS Antioxidants attenuate high glucose-induced hypertrophic growth in renal tubular epithelial cells. Am J Physiol Renal Physiol 293: F1072-F1082, 2007.
9. Du W, Hong J, Wang YC, Zhang YJ, Wang P, Su WY, Lin YW, Lu R, Zou WP, Xiong H, et al: Inhibition of JAK2/STAT3 signalling induces colorectal cancer cell apoptosis via mitochondrial pathway. J Cell Mol Med 16: 1878-1888, 2012.

10. Niu G, Wright KL, Huang M, Song L, Haura E, Turkson J, Zhang S, Wang T, Sinibaldi D, Coppola D, et al: Constitutive Stat3 activity up-regulates VEGF expression and tumor angiogenesis. Oncogene 21: 2000-2008, 2002.

11. Xie TX, Huang FJ, Aldape KD, Kang SH, Liu M, Gershenwald JE, Xie K, Sawaya R and Huang S: Activation of stat3 in human melanoma promotes brain metastasis. Cancer Res 66: 3188-3196, 2006.

12. Nam S, Xie J, Perkins A, Ma Y, Yang F, Wu J, Wang Y, Xu RZ, Huang W, Horne DA, et al: Novel synthetic derivatives of the natural product berbamine inhibit Jak2/Stat 3 signaling and induce apoptosis of human melanoma cells. Mol Oncol 6: 484-493, 2012.

13. Um HJ, Min KJ, Kim DE and Kwon TK: Withaferin A inhibits JAK/STAT3 signaling and induces apoptosis of human renal carcinoma Caki cells. Biochem Biophys Res Commun 427: 24-29, 2012.

14. Park JH, Darvin P, Lim EJ, Joung YH, Hong DY, Park EU, Park SH, Choi SK, Moon ES, Cho BW, et al: Hwanggeumchal sorghum induces cell cycle arrest, and suppresses tumor growth and metastasis through Jak2/STAT pathways in breast cancer xenografts. PLoS One 7: e40531, 2012.

15. Wagner EF and Nebreda AR: Signal integration by JNK and p38 MAPK pathways in cancer development. Nat Rev Cancer 9: 537-549, 2009.

16. Park WH: MAPK inhibitors differentially affect gallic acid-induced human pulmonary fibroblast cell growth inhibition. Mol Med Rep 4: 193-204, 2011.

17. You BR and Park WH: The effects of mitogen-activated protein kinase inhibitors or small interfering RNAs on gallic acid induced HeLa cell death in relation to reactive oxygen species and glutathione. J Agric Food Chem 59: 763-771, 2011.

18. Chen YC, Chang CN, Hsu HC, Chiou SJ, Lee LT and Hseu TH: Sennoside B inhibits PDGF receptor signaling and cell proliferation induced by PDGF-BB in human osteosarcoma cells. Life Sci 84: 915-922, 2009.

19. Noh K, Kim KO, Patel NR, Staples JR, Minematsu H, Nair K and Lee FY: Targeting inflammatory kinase as an adjuvant treatment for osteosarcomas. J Bone Joint Surg Am 93: 723-732, 2011.

20. Gordaliza M: Natural products as leads to anticancer drugs. Clin Transl Oncol 9: 767-776, 2007.

21. Pezzuto JM: Plant-derived anticancer agents. Biochem Pharmacol 53: 121-133, 1997.

22. Ahmad A, Sakr WA and Rahman KM: Novel targets for detection of cancer and their modulation by chemopreventive natural compounds. Front Biosci (Elite Ed) 4: 410-425, 2012.

23. Hijová E, Szabadosova V, Stofilová J and Hrčková G: Chemopreventive and metabolic effects of inulin in colon cancer development. J Vet Sci 14: 387-393, 2013.

24. Park EJ and Pezzuto JM: Antioxidant marine products in cancer chemoprevention. Antioxid Redox Signal 19: 115-138, 2013.

25. Chen JC, Chiu MH, Nie RL, Cordell GA and Qiu SX: Cucurbitacins and cucurbitane glycosides: Structures and biological activities. Nat Prod Rep 22: 386-399, 2005.

26. Geissman TA: New substances of plant origin. Annu Rev Pharmacolog 4: 305-316, 1964.

27. Farias MR, Schenkel EP, Mayer R and Rücker G: Cucurbitacins as constituents of Wilbrandia ebracteata. Planta Med 59: 272-275, 1993

28. Peters RR, Farias MR and Ribeiro-do-Valle RM: Anti-inflammatory and analgesic effects of cucurbitacins from Wilbrandia ebracteata. Planta Med 63: 525-528, 1997.

29. Blaskovich MA, Sun J, Cantor A, Turkson J, Jove R and Sebti SM: Discovery of JSI-124 (cucurbitacin I), a selective Janus kinase/signal transducer and activator of transcription 3 signaling pathway inhibitor with potent antitumor activity against human and murine cancer cells in mice. Cancer Res 63: 1270-1279, 2003.

30. Shi X, Franko B, Frantz C, Amin HM and Lai R: JSI-124 (cucurbitacin I) inhibits Janus kinase-3/signal transducer and activator of transcription-3 signalling, downregulates nucleophosmin-anaplastic lymphoma kinase (ALK), and induces apoptosis in ALK-positive anaplastic large cell lymphoma cells. Br J Haematol 135: 26-32, 2006.

31. Tannin-Spitz T, Grossman S, Dovrat S, Gottlieb HE and Bergman M: Growth inhibitory activity of cucurbitacin glucosides isolated from Citrullus colocynthis on human breast cancer cells. Biochem Pharmacol 73: 56-67, 2007. 
32. Yin D, Wakimoto N, Xing H, Lu D, Huynh T, Wang X, Black KL and Koeffler HP: Cucurbitacin B markedly inhibits growth and rapidly affects the cytoskeleton in glioblastoma multiforme. Int J Cancer 123: 1364-1375, 2008.

33. Ho YT, Yang JS, Li TC, Lin JJ, Lin JG, Lai KC, Ma CY, Wood WG and Chung JG: Berberine suppresses in vitro migration and invasion of human SCC-4 tongue squamous cancer cells through the inhibitions of FAK, IKK, NF-kappaB, u-PA and MMP-2 and -9. Cancer Lett 279: 155-162, 2009.

34. Mizoguchi H, Nakade J, Tachibana M, Ibi D, Someya E, Koike H, Kamei H, Nabeshima T, Itohara S, Takuma K, et al: Matrix metalloproteinase-9 contributes to kindled seizure development in pentylenetetrazole-treated mice by converting pro-BDNF to mature BDNF in the hippocampus. J Neurosci 31: 12963-12971, 2011.

35. Bradford MM: A rapid and sensitive method for the quantitation of microgram quantities of protein utilizing the principle of protein-dye binding. Anal Biochem 72: 248-254, 1976.

36. Güllü IH, Kurdoğlu M and Akalin I: The relation of gelatinase (MMP-2 and -9) expression with distant site metastasis and tumour aggressiveness in colorectal cancer. Br J Cancer 82: 249, 2000.

37. Kilian M, Gregor JI, Heukamp I, Hanel M, Ahlgrimm M, Schimke I, Kristiansen G, Ommer A, Walz MK, Jacobi CA and Wenger FA: Matrix metalloproteinase inhibitor RO 28-2653 decreases liver metastasis by reduction of MMP-2 and MMP-9 concentration in BOP-induced ductal pancreatic cancer in Syrian Hamsters: Inhibition of matrix metalloproteinases in pancreatic cancer. Prostaglandins Leukot Essent Fatty Acids 75: 429-434, 2006.

38. Mizutani K, Kofuji K and Shirouzu K: The significance of MMP-1 and MMP-2 in peritoneal disseminated metastasis of gastric cancer. Surg Today 30: 614-621, 2000.

39. Qazi A, Pal J, Maitah M, Fulciniti M, Pelluru D, Nanjappa P, Lee S, Batchu RB, Prasad M, Bryant CS, et al: Anticancer activity of a broccoli derivative, sulforaphane, in barrett adenocarcinoma: Potential use in chemoprevention and as adjuvant in chemotherapy. Transl Oncol 3: 389-399, 2010.

40. Hartojo W, Silvers AL, Thomas DG, Seder CW, Lin L, Rao H, Wang Z, Greenson JK, Giordano TJ, Orringer MB, et al: Curcumin promotes apoptosis, increases chemosensitivity, and inhibits nuclear factor kappaB in esophageal adenocarcinoma. Trans Oncol 3: 99-108, 2010

41. Martinou JC and Youle RJ: Mitochondria in apoptosis: Bcl-2 family members and mitochondrial dynamics. Dev Cell 21 92-101, 2011.

42. Monian P and Jiang X: Clearing the final hurdles to mitochondrial apoptosis: Regulation post cytochrome $\mathrm{C}$ release. Exp Oncol 34: 185-191, 2012

43. Soriano ME and Scorrano L: The interplay between BCL-2 family proteins and mitochondrial morphology in the regulation of apoptosis. Adv Exp Med Biol 687: 97-114, 2010.

44. Kiu H and Nicholson SE: Biology and significance of the JAK/STAT signalling pathways. Growth Factors 30: 88-106, 2012.

45. Chau MN and Banerjee PP: Development of a STAT3 reporter prostate cancer cell line for high throughput screening of STAT3 activators and inhibitors. Biochem Biophys Res Commun 377: 627-631, 2008

46. Yue P and Turkson J: Targeting STAT3 in cancer: How successful are we? Expert Opin Investig Drugs 18: 45-56, 2009.

47. Chambliss OL and Jone CM: Cucurbitacins: Specific insect attractants in Cucurbitaceae. Science 153: 1392-1393, 1966.

48. Yesilada E, Tanaka S, Sezik E and Tabata M: Isolation of an anti-inflammatory principle from the fruit juice of Ecballium elaterium. J Nat Prod 51: 504-508, 1988

49. Zhang M, Zhang H, Sun C, Shan X, Yang X, Li-Ling J and Deng Y: Target constitutive activation of signal transducer and activator of transcription 3 in human hepatocellular carcinoma cells by cucurbitacin B. Cancer Chemother Pharmacol 63: 635-642, 2009.
50. Wakimoto N, Yin D, O'Kelly J, Haritunians T, Karlan B, Said J, Xing $\mathrm{H}$ and Koeffler HP: Cucurbitacin B has a potent antiproliferative effect on breast cancer cells in vitro and in vivo. Cancer Sci 99: 1793-1797, 2008

51. Li Y, Li W, Chen X, Jiang H, Sun J, Chen H and Lv S: Integrated analysis identifies interaction patterns between small molecules and pathways. Biomed Res Int 2014: 931825, 2014.

52. Wen D, Danquah M, Chaudhary AK and Mahato RI: Small molecules targeting MicroRNA for cancer therapy: Promises and obstacles. J Control Release 219: 237-247, 2015.

53. Wondrak GT, Villeneuve NF, Lamore SD, Bause AS, Jiang T and Zhang DD: The cinnamon-derived dietary factor cinnamic aldehyde activates the Nrf2-dependent antioxidant response in human epithelial colon cells. Molecules 15: 3338-3355, 2010.

54. Liang CZ, Zhang X, Li H, Tao YQ, Tao LJ, Yang ZR, Zhou XP, Shi ZL and Tao HM: Gallic acid induces the apoptosis of human osteosarcoma cells in vitro and in vivo via the regulation of mitogen-activated protein kinase pathways. Cancer Biother Radiopharm 27: 701-710, 2012.

55. Liu Z, Li D, Zhao W, Zheng X, Wang J and Wang E: A potent lead induces apoptosis in pancreatic cancer cells. PLoS One 7: e37841, 2012.

56. Gross A, McDonnell JM and Korsmeyer SJ: Bcl-2 family members and the mitochondria in apoptosis. Genes Dev 13: 1899-1911, 1999.

57. Reed JC: Apoptosis-regulating proteins as targets for drug discovery. Trends Mol Med 7: 314-319, 2001.

58. Yang SH, Chien CM, Lu MC, Lin YH, Hu XW and Lin SR: Upregulation of Bax and endonuclease $\mathrm{G}$, and down-modulation of Bcl-XL involved in cardiotoxin III-induced apoptosis in K562 cells. Exp Mol Med 38: 435-444, 2006.

59. Coussens LM and Werb Z: Matrix metalloproteinases and the development of cancer. Chem Biol 3: 895-904, 1996.

60. Zhang L, Shi J, Feng J, Klocker H, Lee C and Zhang J: Type IV collagenase (matrix metalloproteinase-2 and -9) in prostate cancer. Prostate Cancer Prostatic Dis 7: 327-332, 2004.

61. O'Shea JJ, Gadina M and Schreiber RD: Cytokine signaling in 2002: New surprises in the Jak/Stat pathway. Cell 109 (Suppl): 121-131, 2002.

62. Yu H, Pardoll D and Jove R: STATs in cancer inflammation and immunity: A leading role for STAT3. Nat Rev Cancer 9: 798-809, 2009.

63. Yu H and Jove R: The STATs of cancer-new molecular targets come of age. Nat Rev Cancer 4: 97-105, 2004.

64. Epling-Burnette PK, Liu JH, Catlett-Falcone R, Turkson J, Oshiro M, Kothapalli R, Li Y, Wang JM, Yang-Yen HF, Karras J, et al: Inhibition of STAT3 signaling leads to apoptosis of leukemic large granular lymphocytes and decreased Mcl-1 expression. J Clin Invest 107: 351-362, 2001.

65. Liu T, Zhang M, Zhang H, Sun C and Deng Y: Inhibitory effects of cucurbitacin B on laryngeal squamous cell carcinoma. Eur Arch Otorhinolaryngol 265: 1225-1232, 2008.

66. Johnson GL and Lapadat R: Mitogen-activated protein kinase pathways mediated by ERK, JNK, and p38 protein kinases. Science 298: 1911-1912, 2002.

67. Kim BM and Chung HW: Desferrioxamine (DFX) induces apoptosis through the p38-caspase8-Bid-Bax pathway in PHA stimulated human lymphocytes. Toxicol Appl Pharmacol 228: 24-31, 2008.

68. Mendes O, Kim HT, Lungu G and Stoica G: MMP2 role in breast cancer brain metastasis development and its regulation by TIMP2 and ERK1/2. Clin Exp Metastasis 24: 341-351, 2007.

69. Peng L, Xing X, Li W, Qu L, Meng L, Lian S, Jiang B, Wu J and Shou C: PRL-3 promotes the motility, invasion, and metastasis of LoVo colon cancer cells through PRL-3-integrin beta1-ERK1/2 and-MMP2 signaling. Mol Cancer 8: 110, 2009. 